\title{
Health Publica
}

\section{GAMBARAN STRES KERJA PADA PERAWAT RUMAH SAKIT UMUM HOLISTIC PURWAKARTA}

\author{
Giri Arum Khoirunnisa, Dwi Nurmawaty, Rini Handayani, Gisely Vionalita \\ Program studi Kesehatan Masyarakat, Fakultas Ilmu-Ilmu Kesehatan Universitas Esa Unggul \\ Correspondence author : giriarumkhoirunnisa@gmail.com
}

\begin{abstract}
Work stress is an excessive workload, feelings of distress and emotional tension that hinders individual performance. Job stress can be influenced by organizational conditions such as setting direction and organizational policies, changes in organizational strategy, finances, work demands, responsibilities for others, changes in working time, unfavorable changes between work groups and role conflicts. This study aims to determine the description of work stress in outpatient nurses at the Purwakarta Holistic General Hospital in 2020. This study uses a quantitative method with a cross sectional research design. The research population comprised all 25 outpatient nurses. The sample in this study amounted to 20 outpatient nurses at the General Hospital Holistic Purwakarta with a total sampling technique. The method of collecting data sources of information used is primary data using a measuring instrument in the form of a questionnaire. The results showed that outpatient nurses had a light stress level of $55 \%$, a moderate stress level of $40 \%$, and a severe stress level of $5 \%$. The workload of outpatient nurses shows that $50 \%$ have a light workload and $50 \%$ of nurses experience a heavy workload. The gender of outpatient nurses is $55 \%$ male and $45 \%$ female. The tenure of outpatient nurses $80 \%$ had a service life of more than 5 years and $20 \%$ had a service life of less than 5 years. The conclusion is that there are 11 nurses who experience mild work stress, of the 11 nurses who have mild work stress, there are 6 nurses who have a mild monkey load and 5 nurses who have a moderate workload. Of the 11 nurses who experienced mild stress, 8 nurses were male and 3 nurses were female, and of the 11 nurses there were 4 nurses who had a service period of less than 5 years and 7 nurses had a service period of more than 5 years. To prevent the occurrence of stress on outpatient nurses, the researchers suggested creating a stress control program such as sharing with other nurses or refreshing in turn and adding human resources to units that lacked human resources.
\end{abstract}

Keywords : Work stress, outpatient care, workload

\section{Abstrak}

Stres kerja merupakan beban kerja yang berlebihan, perasaan susah dan ketegangan emosional yang menghambat performance individu. Stres kerja dapat dipengaruhi oleh kondisi organisasi seperti penetapan arah dan kebijaksanaan organisasi, perubahan strategi organisasi, keuangan, tuntutan kerja, tanggung jawab atas orang lain, perubahan waktu kerja, perubahan yang kurang baik antar kelompok kerja dan konflik peran. Penelitian ini bertujuan untuk mengetahui gambaran stres kerja pada perawat rawat jalan di Rumah Sakit Umum Holistic Purwakarta tahun 2020. Penelitian ini menggunakan metode kuantitatif dengan desain penelitian cross sectional. Populasi penelitian ini adalah seluruh perawat rawat jalan sebanyak 25 perawat. Sampel pada penelitian ini berjumlah 20 perawat rawat jalan di Rumah Sakit Umum Holistic Purwakarta dengan teknik sampling total sampling. Metode pengumpulan data sumber informasi yang digunakan yaitu berupa data primer dengan menggunakan alat ukur berupa kuisioner. Hasil penelitian menunjukkan bahwa perawat rawat jalan yang memiliki tingkat stres ringan sebanyak 55\%, tingkat stres sedang sebanyak 40\%, 
dan tingkat stres berat 5\%. Beban kerja pada perawat rawat jalan menunjukkan bahwa 50\% mengalami beban kerja ringan dan 50\% perawat mengalami beban kerja berat. Jenis kelamin perawat rawat jalan laki-laki sebanyak $55 \%$ dan perempuan sebanyak $45 \%$. Masa kerja perawat rawat jalan $80 \%$ memiliki masa kerja lebih dari 5 tahun dan 20\% memiliki masa kerja kurang dari sama dengan 5 tahun. Kesimpulannya terdapat 11 perawat yang mengalami stres kerja ringan, dari 11 perawat yang mengalami stres kerja ringan terdapat 6 perawat yang memiliki beban kera ringan dan 5 perawat memiliki beban kerja sedang. Dari 11 perawat yang mengalami stres ringan terdapat 8 perawat berjenis kelamin laki-laki dan 3 perawat berjenis kelamin perempuan, serta dari 11 perawat tersebut terdapat 4 perawat memiliki masa kerja kurang dari sama dengan 5 tahun dan 7 perawat memiliki masa kerja lebih dari 5 tahun. Untuk mencegah terjadinya stres pada perawat rawat jalan maka peneliti menyarankan untuk membuat program pengendalian stres seperti mengadakan sharing ke perawat lain atau refreshing secara bergantian serta melakukan penambahan SDM pada unit yang kekurangan SDM.

Kata Kunci : Stres Kerja, Rawat Jalan, Beban Kerja

\section{PENDAHULUAN}

Menurut WHO, Rumah Sakit adalah bagian integral dari suatu organisasi sosial dan kesehatan dengan fungsi menyediakan pelayanan paripurna (komprehensif), Penyembuhan penyakit (kuratif), dan pecegahan penyakit (preventif) kepada masyarakat. Rumah sakit merupakan pusat pelatihan bagi tenaga kesehatan dan penelitian medik. Rumah sakit adalah institusi pelayanan kesehatan yang menyelenggarakan pelayanan kesehatan perorangan secara paripurna yang mnyediakan pelayanan rawat inap, rawat jalan dan gawat darurat (Permenkes, 2018).

Semakin meningkatnya kebutuhan manusia saat ini khususnya di bidang kesehatan yang semakin kompleks, hal ini dapat memempengaruhi meningkatnya tuntutan kerja pada praktisi kesehatan dalam memberikan pelayanan. Rumah sakit diharapkan mampu memberikan layanan kesehatan yang terbaik kepada masyarakat dan diharapkan mampu mewujudkan hal tersebut, sehingga rumah sakit sangat memerlukan tenaga medis yang memiliki kemampuan dalam memberikan pelayanan kesehatan. Pengaturan manajemen SDM di rumah sakit sangat diperlukan, apabila manajemen dilakukan dengan baik maka tidak akan ada lagi SDM Rumah Sakit yang mengalami stres akibat kerja (Islam, 2020).

Stres kerja merupakan beban kerja yang berlebihan, perasaan susah dan ketegangan emosional yang menghambat performance individu. Stress kerja dapat dipengaruhi oleh kondisi organisasi seperti penetapan arah dan kebijaksanaan organisasi, perubahan strategi organisasi, keuangan, tuntutan kerja, tanggung jawab atas orang lain, perubahan waktu kerja, perubahan yang kurang baik antar kelompok kerja dan konflik peran (Pratama, 2013).

American Nurses Asociation (2017), menyatakan bahwa stres pada perawat didapatkan sebanyak $82 \%$ dari pekerja yang ada di rumah sakit di Amerika. Menurut Health and Safety Executive (2019), menunjukkan bahwa tenaga profesional kesehatan, guru, dan perawat memiliki tingkat stres tinggi dengan angka prevalensi sebesar 3000 kasus per 100.000 orang pekerja. Perawat dan mahasiswa keperawatan menghadapi bahaya yang unik di tempat kerja, dengan ini menunjukkan harus ada cara untuk menanggulangi tingkat stres pada perawat, terutama dengan aktivitas fisik, nutrisi, istirahat, keamanan dan kualitas hidup (Hendarti, 2020).

Menurut Kementerian Kesehatan RI pada tahun (2017), sebesar 60,6\% pekerja mengalami depresi dan sebesar 57,6\% pekerja mengalami insomnia. Gangguan ini berhubungan dengan 
gangguan mental emosional dan stresor pengembangan karir. Penyebab stres ditempat kerja disebabkan oleh beban pekerjaan, seperti target, hubungan interpersonal, dengan atasan atau rekan kerja lain. Hasil survei yang dilakukan PPNI (2018), menyatakan bahwa sekitar 50,9\% perawat di Indonesia mengalami stres kerja (Hendarti, 2020).

Menurut (Hendarti, 2020) beberapa faktor yang menyebabkan stres pada perawat diantaranya adalah faktor pekerjaan, faktor individu dan faktor pendukung. Adapun faktor pekerjaan adalah lingkungan fisik, konflik interpersonal, beban kerja, dan shift kerja. Adapun faktor individunya adalah umur, status pernikahan, masa kerja dan jenis kelamin, sedangkan faktor pendukungnya adalah dukungan sosial.

Dampak stres kerja yang dialami pekerja di tempat kerja dapat memunculkan perubahan terhadap individu yang mengalami stres. Perubahan yang muncul biasanya seperti bekerja melewati batas kemampuan, sering terlambat masuk kerja, tidak hadir kerja, kesulitan berhubungan dengan orang lain, kerisauan tentang kesalahan yang dibuat, radang kulit dan radang pernafasan (Hendarti, 2020).

Rumah Sakit Umum Holistic Purwakarta merupakan rumah sakit swasta yang berada di Kabupaten Purwakarta. Rumah Sakit Umum Holistic Purwakarta merupakan rumah sakit tipe C yang memiliki pelayanan Rawat Inap, Rawat Jalan, dan Instalasi Gawat Darurat. Pelayanan Rawat jalan yang ada di RSU Holistic Purwakarta adalah Rawat Jalan Poli Dalam, Poli Anak, Poli Gigi, Poli Radiologi, dan Fisioterapi. RSU Holistic Purwakarta pada tahun 2020 memiliki jumlah perawat rawat jalan sebanyak 25 perawat.

Perawat rawat jalan RSU Holistic Purwakarta terdiri dari 14 perawat laki-laki, dan 11 perawat perempuan. Perawat rawat jalan yang memiliki masa kerja $>5$ tahun berjumlah 21 perawat, sedangkan yang memiliki masa kerja $<5$ tahun berjumlah 4 perawat. Sistem kerja perawat rawat jalan RSU Holistic Purwakarta dilakukan secara shift. Shift kerja perawat Rawat Jalan dibagi menjadi dua shift, yaitu shift pagi dan shift siang. Shift pagi dimulai dari jam 8.00 - 16.00, sedangkan shift siang dimulai dari jam 10.00-18.00.

Perawat rawat jalan di RSU Holitic Purwakarta melaksanakan pekerjaannya sesuai dengan jobdesknya masing-masing, sehingga semua perawat menangani semua pasien dengan kondisi serta keadaan pasien yang berbeda-beda. Perawat rawat jalan dituntut untuk melakukan tugas dengan cepat dan tepat. Hal ini dikarenakan setiap perawat rawat jalan dalam 1 hari dapat memegang pasien sebanyak 25-30 pasien dengan keadaan dan kondisi yang berbeda-beda. Jobdesk Perawat rawat jalan RSU Holistic Purwakarta selain memeriksa keadaan pasien, perawat rawat jalan juga menyiapkan alat untuk pemeriksaan, mengisi lembar anamnesa pasien, mengantarkan pasien masuk ke poli untuk diperiksa dokter, melaporkan kondisi pasien kepada dokter, mengangkat pasien ke tempat pemeriksaan apabila pasien tidak kuat untuk jalan, mengantarkan pasien ke ruang lab atau radiologi apabila dirujuk oleh dokter untuk pemeriksaan lanjutan, memberikan penjelasan kepada keluarga pasien apabila keluarga kurang paham dengan apa yang di sampaikan dokter, membersihkan ruangan pemeriksaan setelah dokter selesai praktek. Banyaknya tugas perawat rawat jalan di RSU Holistic Purwakarta dapat menimbulkan beban kerja yang berlebihan, sehingga perawat mudah mengalami stres yang mengganggu fisik, psikis dan proses berfikir. Hal ini dapat menggangu keselamatan pasien. Berdasarkan data dari bagian mutu RSU Holistic Purwakarta performa kerja perawat dan terapis selama 3 tahun terakhir mengalami penurunan setiap tahunnya. Hal ini terjadi akibat beban kerja tinggi yang menyebabkan stres pada perawat rawat jalan.

Hasil survey pendahuluan yang dilakukan di Rumah Sakit Umum Holistic Purwakarta pada tanggal 12 Januari 2021, dengan membagikan kuisioner Depression Anxiety Stress Scale (DASS 42) kepada 5 responden perawat rawat jalan mendapatkan hasil bahwa $2(40 \%)$ responden mengalami tingkat stres berat, $1(20 \%)$ responden mengalami stres sedang, dan 
$2(40 \%)$ responden mengalami stres ringan. Perawat yang memiliki tingkat stres berat ditandai dengan sulitnya berelaksasi/ bersantai, sering merasa kesal, cemas, sulit untuk istirahat, mudah merasa marah, dan mudah tersinggung. Dua perawat yang mengalami stres berat berjenis kelamin perempuan, berstatus sudah menikah, dan memiliki masa kerja $>5$ tahun. Pengkategorian tingkat stres berdasarkan kuisioner DASS 42 terbagi menjadi 5 kategori yaitu normal (skor 0-14), Ringan (Skor 15-18), Sedang (Skor 19-25), Berat (Skor 26-33) dan Sangat Berat (skor $>33$ ).

Berdasarkan hasil wawancara dengan koordinator perawat rawat jalan RSU Holistic Purwakarta didapatkan bahwa pada bulan November 2020 terdapat 6 perawat rawat jalan yang tidak masuk kerja dikarenakan sakit. Hal ini dapat mempengaruhi kinerja rumah sakit secara keseluruhan. Berdasarkan survey kepuasan pasien pada bulan November 2020 mendapatkan hasil $28 \%$, pasien tidak puas dengan pelayanan rawat jalan RSU Holistic Purwakarta. Berdasarkan hasil wawancara dengan HRD RSU Holistic Purwakarta didapatkan informasi bahwa setiap harinya pasti ada perawat rawat jalan atau terapis yang telat masuk kerja.

Berdasarkan tujuan penelitian di RSU Holistic Purwakarta, maka penulis perlu melakukan penelitian stres kerja yang disebabkan karena beban kerja yang dirasa berlebihan oleh perawat rawat jalan. Kondisi ini apabila tidak dikelola dengan baik maka perawat rawat jalan akan kehilangan konsentrasi yang dapat membahayakan keselatan pasien. Maka dari itu penulis merasa perlu untuk mengambil penelitian dengan judul "Gambaran Stres Kerja Pada Perawat Rawat Jalan Di Rumah Sakit Umum Holistic Purwakarta Tahun 2020”.

\section{METODE}

\section{Rancangan Penelitian}

Penelitian ini dilakukan di ruang rawat jalan RSU Holistic Purwakarta. Penelitian ini dilakukan pada bulan September 2020 - Februari 2021. Penelitian ini menggunakan jenis penelitian kuantitatif dengan rancangan penelitian survey analitik dan menggunakan pendekatan cross sectional yaitu rancangan penelitian yang dilakukan untuk mengetahui variabel independen dan dependen dimana pengukurannya dilakukan pada satu waktu. Pengumpulan data pada penelitian ini menggunakan data primer yang diperoleh berdasarkan hasil wawancara dengan menggunakan kuisioner. Kuisioner yang digunakan untuk variabel stres kerja adalah Depression Anxiety Stress Scale (DASS 42) yang berjumlah 14 soal dengan empat pilihan jawaban yaitu tidak pernah, kadang-kadang, sering dan selalu. Sedangkan untuk beban kerja peneliti menggunakan kuisioner dari Nursalam, 2016 yang berjumlah 13 soal dengan empat pilihan jawaban yaitu tidak menjadi beban kerja, beban kerja ringan, beban kerja sedang, dan beban kerja berat. Untuk Variabel jenis kelamin berisi 2 pilihan yaitu lakilaki dan perempuan sedangkan untuk masa kerja terdapat dua pilihan yaitu masa kerja $\leq 5$ tahun dan $>5$ tahun.

\section{Subjek Penelitian}

Populasi dalam penelitian ini adalah seluruh perawat rawat jalan di RSU Holistic Purwakarta Tahun 2020 sebanyak 25 responden. Teknik pengambilan sampel pada penelitian ini menggunakan teknik total sampling yaitu karena jumlah populasi kurang dari 30 responden maka semua populasi dijadikan sampel. Jumlah sampel yang digunakan peneliti berjumlah 20 responden dikarenakan 5 responden sudah digunakan saat peneliti melakukan survey pendahuluan. 


\section{Health Publica}

\section{HASIL}

\section{ANALISIS UNIVARIAT}

Tabel 1. Distribusi frekuensi karakteristik stres kerja, beban kerja, jenis kelami, dan masa kerja

\begin{tabular}{l|l|l}
\hline Karakteristik & $\begin{array}{l}\text { Frekuensi } \\
(\mathrm{n}=20)\end{array}$ & $\begin{array}{l}\text { Presentase } \\
(\%)\end{array}$ \\
\hline $\begin{array}{l}\text { Stres Kerja } \\
\text { Stres Ringan }\end{array}$ & 11 & $55 \%$ \\
$\begin{array}{l}\text { Stres Sedang } \\
\text { Stres Berat }\end{array}$ & 8 & $\begin{array}{l}40 \% \\
5 \%\end{array}$ \\
\hline $\begin{array}{l}\text { Beban Kerja } \\
\text { Beban Kerja } \\
\text { Ringan Kerja }\end{array}$ & 10 & $50 \%$ \\
$\begin{array}{l}\text { Beban } \begin{array}{l}\text { Berat } \\
\text { Jenis Kelamin } \\
\text { Perempuan }\end{array} \\
\text { Laki-laki }\end{array}$ & 10 & $50 \%$ \\
\hline $\begin{array}{l}\text { Masa Kerja } \\
\leq 5 \text { Tahun }\end{array}$ & 11 & $45 \%$ \\
$>5$ Tahun & $45 \%$ \\
\hline \multicolumn{2}{c}{ Keterangan : n jumlah sampel }
\end{tabular}

Jumlah total perawat rawat jalan di RSU Holistic Purwakarta adalah 25 orang. Lima orang sudah digunakan untuk studi pendahuluan, sehingga total sampel 20 orang. Penelitian dilakukan pada bulan Agustus 2020 sampai dengan Februari 2021.

Berdasarkan tabel 1 dapat dilihat bahwa dari 20 responden, frekuensi terbanyak adalah responden yang memiliki masa kerja lebih dari 5 tahun yaitu $80 \%$ dan didominasi oleh perawat yang berjenis kelamin perempuan yaitu berjumlah 9 responden (45\%). Di RSU Holistic Purwakarta benyak perawat rawat jalan yang mengalami stres ringan yaitu sebanyak 11 perawat (55\%) dan stres sedang sebanyak 8 perawat (40\%). Responden yang mengalami beban kerja ringan sebanyak 10 orang $(50 \%)$.

\section{PEMBAHASAN}

\section{Analisis Univariat}

\subsection{Gambaran Stres Kerja Pada Perawat Rawat Jalan Di RSU Holistic Purwakarta Tahun 2020}

Berdasarkan hasil penelitian yang telah dilakukan dengan menggunakan kuisioner Depression Anxiety Stress Scale (DASS) pada 20 perawat rawat jalan RSU Holistic Purwakarta Tahun 2020, diketahui bahwa pekerja yang mengalami stres kerja dibagi menjadi 3 kategori yaitu tingkat stres ringan, tingkat stres sedang dan tingkat stres berat.

Proporsi tertinggi adalah perawat yang mengalami stres kerja ringan yaitu berjumlah 11 perawat $(55 \%)$. Hasil penelitian ini sejalan dengan penelitian yang telah dilakukan oleh (Ismail, 2013), bahwa perawat rawat jalan yang mengalami stres ringan sebanyak 80,6\%. Penelitian lain yang dilakukan (Rhamdani \& Wartono, 2019) menunjukkan hasil bahwa perawat rawat jalan yang mengalami stres kerja sebanyak $74,5 \%$.

Stres kerja merupakan beban kerja yang berlebihan, perasaan susah dan ketegangan emosional yang menghambat performance individu. Stres kerja dapat dipengaruhi oleh kondisi organisasi, keuangan, tuntutan kerja, tangung jawab atas orang lain, perubahan waktu 
kerja, perubahan yang kurang baik antar kelompok kerja dan konflik peran(Pratama, 2013). Faktor yang dapat menyebabkan stres kerja diantaranya adalah faktor pekerjaan, faktor individu, dan faktor pendukung. Faktor pekerjaan diantaranya adalah lingkungan fisik, konflik interpersonal, beban kerja dan shift kerja. Faktor individu yang dapat menyebabkan stres kerja diantaranya yaitu umur, jenis kelamin, masa kerja dan status pernikahan, serta faktor pendukung nya yaitu dukungan sosial. Dampak stres kerja yang dialami pekerja di tempat kerja dapat memunculkan perubahan terhadap individu,antara lain bekerja melewati batas, sering terlambat masuk kerja, tidak hadir kerja, kesulitan hubungan dengan orang lain, gelisah dengan kesalahan yang dibuat, radang kulit, dan radang pernafasan(Hendarti, 2020).

Berdasarkan hasil jawaban kuisioner Depression Anxiety Stress Scale (DASS) pada perawat rawat jalan RSU Holistic Purwakarta didapatkan hasil bahwa 55\% perawat rawat jalan mengalami stres kerja ringan, 40\% perawat rawat jalan mengalami stres kerja sedang dan $5 \%$ perawat rawat jalan mengalami stres kerja berat. Berdasarkan hasil wawancara pada perawat rawat jalan yang memiliki tingkat stres sedang memiliki jenis kelamin perempuan dan berstatus sudah menikah. Perawat yang memiliki tingkat stres sedang menyatakan bahwa perawat merasa memiliki peran ganda yaitu sebagai perawat rawat jalan di RSU Holistic Purwakarta dan sebagai ibu rumah tangga ketika di rumah. Hal ini dapat menyebabkan perawat merasakan stres pada diri nya.

Berdasarkan hasil wawancara dengan koordinator perawat rawat jalan mendapatkan hasil bahwa perawat banyak yang mengalami stres kerja ringan disebabkan oleh beberapa faktor yaitu dari beban kerja, jenis kelamin dan masa kerja. Seiring bertambahnya beban kerja yang didapatkan oleh perawat maka semakin tinggi pula perawat mengalami stres kerja. Perawat yang memiliki stres kerja dan beban kerja berat adalah perawat yang memiliki kedudukan lebih tinggi seperti perawat yang menjadi penanggung jawab, dan perawat yang diruangannya kekurangan SDM. Faktor yang mempengaruhi stres kerja pada perawat diantaranya yaitu karena kurangnya jumlah SDM pada divisi rawat jalan, beban kerja yang tinggi, keadaan pasien yang berbeda-beda, dan tuntutan dari atasan untuk melaksanakan pelayanan yang berkualitas.

Untuk mencegah terjadinya stres kerja pada perawat rawat jalan, peneliti menyarankan untuk membuat program pengendalian stres seperti mengadakan sharing ke perawat lain atau mengadakan acara refreshing secara bergantian. Program pengendalian stres ini bertujuan agar tingkat stres yang dialami perawat dapat menurun dan perawat dapat melaksakan pekerjaannya dengan tenang dan tepat.

\subsection{Gambaran Stres Kerja Berdasarkan Beban Kerja Pada Perawat Rawat Jalan Di RSU Holistic Purwakarta}

Berdasarkan hasil penelitian variabel beban kerja diketahui bahwa perawat rawat jalan di RSU Holistic Purwakarta, memiliki proporsi yang sama antara beban kerja ringan dan beban kerja berat. Perawat rawat jalan yang mengalami beban kerja ringan sebanyak 10 perawat $(50 \%)$ dan 10 perawat $(50 \%)$ mengalami beban kerja berat. Hal ini sejalan dengan penelitian (Retnaningtyas, 2018) dan (Kusumaningtiar \& Anggraini, 2020), hasil penelitian (Retnaningtyas, 2018) menunjukkan hasil bahwa perawat memiliki beban kerja ringan sebanyak $44,2 \%$ dan perawat memiliki beban kerja berat sebanyak 55,8\%. Sedangkan pada penelitian (Kusumaningtiar \& Anggraini, 2020) menunjukkan hasil bahwa guru mengalami beban kerja ringan sebanyak 10 guru $(14,7)$ dan guru yang memiliki beban ringan sebanyak 58 guru $(85,3 \%)$.

Berdasarkan hasil jawaban yang didapatkan dari kuisioner beban kerja pada perawat rawat jalan di RSU Holistic Purwakarta dari 10 perawat yang memiliki beban kerja ringan terdapat 6 perawat yang mengalami stres kerja ringan dan ada 4 perawat mengalami stres 
kerja sedang. Sedangkan pada 10 perawat yang memiliki beban kerja berat terdapat 5 perawat yang yang mengalami stres kerja ringan, ada 4 perawat mengalami stres kerja sedang dan ada 1 perawat yang mengalami stres kerja berat. Perawat rawat jalan di RSU Holistic Purwakarta merasakan beban kerja yang berat apabila di unit kerjanya kekurangan SDM dibandingkan dengan jumlah pasien, dituntut pimpinan untuk memberikan pelayanan yang berkualitas, menghadapi pasien yang memiliki karakteristik berbeda-beda serta pekerjaan yang menyangkut keselamatan pasien. Hal ini menunjukkan bahwa beban kerja merupakan faktor yang mempengaruhi stres kerja, karena semakin tinggi beban kerja maka semakin tinggi pula tingkat stres kerja yang dialami oleh perawat.

Beban kerja merupakan volume pekerjaan yang dibebankan kepada tenaga kerja, baik fisik maupun mental dan tanggung jawab. Beban kerja yang berlebihan terjadi ketika seseorang merasa kurang dalam keahliannya atau sumber daya waktu untuk menyelesaikan pekerjaan tertentu. Faktor yang mempengaruhi beban kerja diantaranya adalah jumlah pasien yang ditangani setiap harinya, kondisi penyakit dan tingkat ketergantungan pasien, dan frekuensi tindakan (Puri, 2018). Beban kerja dapat mengurangi tingkat psikologis yang tinggi. Tingkat stres dan kelelahan yang tinggi secara fisik dan emosional dari waktu ke waktu dapat meningkatkan risiko kesehatan seperti penyakit jantung, dan penyakit pernafasan (Kusumaningtiar \& Anggraini, 2020). Beban kerja yang berlebihan dapat memicu munculnya stres kerja bagi perawat. Stres kerja dapat dipicu dari kondisi kerja yang buruk, kelebihan beban kerja, pekerjaan yang tidak lagi menantang atau pada pekerjaa yang berisiko tinggi. Jika masalah beban kerja tidak dilakukan penanganan, maka dikhawatirkan stres kerja yang semakin tinggi akan dialami oleh perawat (Retnaningtyas, 2018). Hal ini sejalan dengan hasil penelitian yang menunjukkan bahwa beban kerja yang tinggi dapat menjadi faktor terjadinya stres kerja.

Berdasarkan hasil observasi dan wawancara pada koordinator rawat jalan menyatakan bahwa perawat yang memiliki beban kerja berat adalah perawat yang memiliki kedudukan di divisi rawat jalan. Adapun faktor-faktor yang mempengaruhi beban kerja berat pada perawat rawat jalan diantaranya yaitu tuntunan tugas yang lebih berat kepada penanggung jawab, jumlah SDM yang kurang pada suatu divisi, kemampuan dan ketrampilan perawat yang kurang, dan jumlah pasien yang ditangani untuk setiap harinya.

Untuk mencegah terjadinya beban kerja berat yang mengakibatkan stres kerja, maka peneliti menyarankan untuk melakukan penambahan SDM pada unit yang kekurangan SDM. Penambahan SDM ini bertujuan agar beban kerja perawat dapat berkurang serta stres kerja pada perawat yang disebabkan karena beban kerja yang berat dapat berkurang juga.

\subsection{Gambaran Distribusi Stres Kerja Berdasarkan Jenis Kelamin pada perawat rawat jalan di RSU Holistic Purwakarta tahun 2020}

Berdasarkan hasil penelitian variabel jenis kelamin diketahui bahwa perawat rawat jalan di RSU Holistic Purwakarta, proporsi tertinggi terdapat pada perawat yang berjenis kelamin laki-laki yaitu sebanyak 11 perawat (55\%) dan perawat berjenis kelamin perempuan sebanyak 9 perawat (45\%). Dari 11 perawat berjenis kelamin laki-laki terdapat 8 perawat yang mengalami stres kerja ringan dan 3 perawat mengalami stres kerja sedang. Sedangkan dari 9 perawat yang berjenis kelamin perempuan terdapat 3 perawat yang mengalami stres ringan, 5 perawat yang mengalami stres sedang dan 1 perawat yang mengalami stres berat.

Jenis kelamin merupakan karakteristik biologis dan fisiologis yang membedakan seorang laki-laki dan perempuan. Dalam kaitannya dengan stres, perempuan mempunyai kecenderungan mangalami stres lebih besar dimana didalam tubuh seorang perempuan terjadi perubahan hormonal. Perempuan lebih mudah merasakan perasaan bersalah, cemas, peningkatan bahkan penurunan nafsu makan, gangguan tidur, dan gangguan makan. Ketika 
stres perempuan lebih mudah untuk sedih, sensitif, marah, serta mudah menangis. Selain perubahan hormonal perempuan lebih mengedepankan emosional dari pada rasional, berbeda dengan laki-laki. Ketika menghadapi masalah perempuan cenderung menggunakan perasaan dibandingkan logika. Laki-laki ketika menghadapi masalah meraka akan cenderung menggunakan logika (Hendarti, 2020).

Berdasarkan hasil wawancara dengan koordinator perawat rawat jalan menyatakan bahwa perawat dengan jenis kelamin perempuan lebih mudah terkena stres kerja. Hal ini terjadi karena perawat perempuan dalam melaksanakan tugasnya biasanya menggunakan perasaan, dan lebih seringnya perawat perempuan yang sudah menikah merasa memiliki tugas ganda yaitu sebagai ibu rumah tangga ketika dirumah dan sebagai perawat ketika di tempat kerja. Sehingga perawat perempuan sering merasa tidak fokus ketika menangani pasien. Pihak Rumah Sakit juga sudah memberikan keringan untuk perawat perempuan diantaranya yaitu memberikan tugas yang lebih ringan kepada perawat perempuan, memberikan kelonggaran cuti atau ijin tidak masuk kerja pada perawat perempuan, pemberlakuan shift kerja pada perempuan lebih banyak di tempatkan di shift pagi dibadingkan dengan shift siang, dan diberikan dispensasi tidak masuk kerja apabila perawat perempuan sedang datang bulan. Perawat laki-laki juga bisa terkena stres kerja apabila tanggung jawabnya di tempat kerja lebih berat dibandingkan perawat perempuan, serta perawat laki-laki dituntut kerja lebih keras dan siap menghadapi ketika perawat perempuan mengalami perubahan hormonal. Untuk mencegah terjadinya stres kerja pada perawat rawat jalan peneliti menyarankan untuk perawat rawat jalan bekerja lebih profesional, tidak membawa permasalah dirumah ke tempat kerja.

\subsection{Gambaran Distribusi Stres Kerja Berdasarkan Masa Kerja Perawat Rawat Jalan Di RSU Holistic Purwakarta Tahun 2020}

Berdasarkan hasil penelitian variabel masa kerja diketahui bahwa perawat rawat jalan di RSU Holistic Purwakarta, proporsi tertinggi terdapat pada perawat yang memiliki masa kerja $>5$ tahun yaitu sebanyak 16 perawat $(80 \%)$. Dari hasil penelitian terdapat 16 perawat yang memiliki masa kerja lebih dari 5 tahun terdapat 7 perawat mengalami stres ringan, 8 perawat mengalami stres sedang dan 1 perawat mengalami stres berat. Sedangkan dari 4 perawat yang memiliki masa kerja kurang dari sama dengan 5 tahun mengalami stres ringan. Hasil penelitian ini sejalan denga penelitian yang dilakukan oleh (Rhamdani, 2019) bahwa perawat yang memiliki masa kerja lebih dari 5 tahun sebanyak 60 perawat (58,9\%).

Masa kerja merupakan kurun waktu atau lamanya tenaga kerja bekerja disuatu tempat. Masa kerja dihitung sejak terjadinya kerja antara pihak perusahaan dengan pekerja. Masa kerja dapat mempengaruhi tenaga kerja baik positif maupun negatif. Masa kerja akan memberikan pengaruh positif kepada pekerja apabila dengan semakin lamanya seorang bekerja maka pekerja tersebut semakin banyak pengalaman dalam menjalankan tugasnya. Namun sebaliknya akan memberikan pengaruh negatif jika semakin lamanya seseorang bekerja maka akan menimbulkan kebosanan dan kelelaan kerja yang berujung pada kerusakan organ tubuh (Hendarti, 2020). Semakin lama masa kerja seorang perawat maka semakin memberikan dampak positif bagi kinerja perawat, dikarenakan masa kerja yang cukup lama maka pengalaman dan wawasan dari para perawat akan semakin meningkat (Sari, 2017).

Berdasarkan hasil observasi dan wawancara terhadap perawat rawat jalan di RSU Holistic Purwakarta, perawat menyatakan bahwa mereka merasa nyaman dengan lingkungan kerja yang baik, dekat dengan rumah perawat, mendapatkan tunjangan dan bonus setiap tahunnya, dan setiap perawat diberikan jaminan kesehatan. Selain itu jika masa kerja perawat lebih dari 2 tahun akan langsung diangkat menjadi karyawan tetap.

Berdasarkan hasil wawancara dengan koordinator perawat rawat jalan, perawat yang mengalami stres kerja sedang dan berat adalah perawat yang memiliki masa kerja lebih dari 5 


\section{Health Publica}

tahun. Perawat yang memiliki masa kerja lebih dari 5 tahun lebih dipercaya untuk mendapatkan tugas dan kedudukan yang lebih tinggi dibandingkan dengan perawat yang memiliki masa kerja kurang dari sama dengan 5 tahun. Hal ini dikarenakan perawat yang memiliki masa kerja lebih dari 5 tahun sudah dapat beradaptasi dengan lingkungan kerjanya, memiliki wawasan dan pengalaman yang lebih baik dibandingkan dengan perawat yang memiliki masa kerja kurang dari 5 tahun.

\section{KESIMPULAN DAN SARAN}

Berdasarkan hasil penelitian terhadap 20 perawat rawat jalan di RSU Holistic Purwakarta tahun 2020 dapat disimpulkan bahwa:

1. Distribusi stres kerja pada perawat rawat jalan di RSU Holistic Purwakarta tahun 2020 dengan proporsi tertinggi adalah perawat yang mengalami stres kerja ringan sebanyak 11 perawat $55 \%$. Untuk mencegah terjadinya stres ringan pada perawat rawat jalan di RSU Holistic Purwakarta maka penulis menyarankan untuk membuat program pengendalian stres seperti mengadakan sharing ke perawat lain atau mengadakan acara Refreshing secara bergantian.

2. Distribusi beban kerja pada perawat rawat jalan di RSU Holistic Purwakarta tahun 2020 dengan proporsi yang sama pada beban kerja ringan dan berat. Besar proporsi beban kerja ringan dan berat adalah 10 perawat 50\% mengalami beban kerja ringan, dan 10 perawat $50 \%$ mengalami beban kerja berat. Untuk mencegah terjadinya stres kerja berdasarkan beban kerja maka peneliti menyarankan untuk menambah SDM pada divisi yang kekurangan jumlah SDM.

3. Distribusi jenis kelamin pada perawat rawat jalan di RSU Holistic Purwakarta tahun 2020 dengan proporsi tertinggi adalah perawat yang berjenis kelamin laki-laki sebanyak 11 perawat $55 \%$.

4. Distribusi masa kerja perawat rawat jalan di RSU Holistic Purwakarta tahun 2020 dengan proporsi tertinggi adalah perawat yang memiliki masa kerja lebih dari 5 tahun sebanyak 16 perawat $80 \%$.

\section{REFERENSI}

Hendarti, R. D. (2020). FAKTOR-FAKTOR YANG BERHUBUNGAN DENGAN STRESS KERJA PADA PERAWAT RAWAT INAP DI RS HERMINA DEPOK PADA TAHUN 2020. Universitas Esa Unggul.

Islam, F. (2020). FAKTOR - FAKTOR YANG BERHUBUNGAN DENGAN TINGKAT SETRES KERJA PADA PERAWAT DI INSTALASI GAWAT DARURAT RUMAH SAKIT SARI ASIH KARAWACI TANGERANG TAHUN 2019 (pp. 1-9). Universitas Esa Unggul.

Ismail, C. suriani. (2013). BEBERAPA FAKTOR YANG BERHUBUNGAN DENGAN STRES KERJA PADA PERAWAT DI RUMAH SAKIT UMUM BAHTERAMAS PROVINSI SULAWESI TENGGARA TAHUN 2013. Universitas Hasanuddin. http://ir.obihiro.ac.jp/dspace/handle/10322/3933

Kusumaningtiar, D. A., \& Anggraini, D. (2020). Factors Related to Work Stress in Elementary School Teachers in East Cengkareng Village During Work From Home. 30(Ichd), 86-91. https://doi.org/10.2991/ahsr.k.201125.016

Permenkes. (2018). Kewajiban Rumah Sakit Dan Kewajiban Pasien (4 Tahun 2018; pp. 1-35).

Pratama, D. A. (2013). Hubungan Tentang Beban Kerja Perawat IGD RSUD Gunung Jati Dengan Prsepsi Stres Kerja Pada Unit IGD RSUD Gunung Jati Kota Cirebon. Universitas Esa Unggul. 


\section{Health Publica}

Jurnal Kesehatan Masyarakat

Puri, I. (2018). Hubungan Beban Kerja Dengan Stres Kerja Pada Perwat IGD RSUD Munyang Kute Redelong. Universitas Medan Area.

Retnaningtyas, L. E. (2018). Pengaruh Beban Kerja Terhadap Stres Kerja Perawat Di Ruangan Rawat Inap Rumah Sakit Islam Siti Aisyah Kota Madiun. Stikes Bhakti Husada Mulia Madiun.

Rhamdani, I., \& Wartono, M. (2019). Hubungan antara shift kerja, kelelahan kerja dengan stres kerja pada perawat. Jurnal Biomedika Dan Kesehatan, 2(3), 104-110. https://doi.org/10.18051/jbiomedkes.2019.v2.104-110

Sari, R. (2017). FAKTOR YANG BERHUBUNGAN DENGAN STRES KERJA PADA PERAWAT DI RUANG RAWAT INAP RUMAH SAKIT JIWA PROVINSI SULAWESI TENGGARA TAHUN 2016 (Vol. 2, Issue 6, pp. 1-10). 